\title{
Economic Efficiency of Stingless Bee Farms in Peninsular Malaysia Estimated by Data Envelopment Analysis (DEA)
}

\author{
Norhidayah Che Soh ${ }^{1,2 *}$, Nur Syahirah Samsuddin ${ }^{1}$ and Mohd Mansor Ismail ${ }^{1}$ \\ ${ }^{1}$ Institute of Agricultural and Food Policy Studies, Universiti Putra Malaysia, Putra Infoport Jalan Kajang- \\ Puchong, 43400 UPM Serdang, Selangor, Malaysia \\ ${ }^{2}$ Faculty of Fisheries and Food Science, Universiti Malaysia Terengganu, 21030 Kuala Nerus, \\ Terengganu, Malaysia
}

\begin{abstract}
The commercial stingless beekeeping industry has good economic growth potential in Malaysia, which is a tropical country rich in flora that serves as food sources for stingless bees. Local consumption of honey is increasing and its production locally can be raised to meet the demand by sustainable stingless beekeeping. An important indicator that measures the success of the industry is the economic efficiency of the farm. This study hence examined the cost efficiency (CE), technical efficiency (TE), and allocative efficiency (AE) of commercial stingless beekeeping farms in the East Coast and Northern regions of Peninsular Malaysia using Cost Data Envelopment Analysis (DEA) under the assumption of Constant Return to Scale (CRS). Interviews with 47 respondents in the East Coast region and 28 respondents in the Northern region showed that the average CE scores for the two regions were 0.291 and 0.172 , respectively. TE for the East Coast region and Northern region were 0.656 and 0.385 while mean $\mathrm{AE}$ scores of 0.445 and 0.404 were obtained. Factors that influenced the efficiency of the farms included farmers' years of schooling and extension officer visits. In conclusion, CE, TE, and AE of commercial stingless bee honey production in Peninsular Malaysia were fairly low, and the determinants responsible for this low efficiency is of

ARTICLE INFO

Article history:

Received: 28 March 2020

Accepted: 08 October 2020

Published: 26 March 2021 concern. Economic efficiency in stingless beekeeping needs to be further elevated to optimise productivity.
\end{abstract}

DOI: https://doi.org/10.47836/pjssh.29.1.34

E-mail addresses:

norhidayah.soh@umt.edu.my (Norhidayah Che Soh) nursyahirahsamsuddin91@gmail.com (Nur Syahirah Samsuddin) mkk@upm.edu.my (Mohd Mansor Ismail)

* Corresponding author 


\section{INTRODUCTION}

Malaysia, located in the tropics, is rich in natural resources with a wide variety of flora and fauna that can contribute to economic growth. Bees are among the abundant fauna species found in Malaysia; they include stingless bees that produce honey for human consumption. Worldwide, there are about 500 species within the stingless bee genus, with most of them found in Latin America, Australia, Africa, and Eastern and Southern Asia (Rasmussen \& Cameron, 2010). They play an important role as the main pollinators for many wild and cultivated tropical plants (Slaa et al., 2006).

According to Ismail (2014), there are about 100 species of bees in Malaysia. The country is suited for stingless beekeeping (meliponiculture) owing to the high diversity of dipterocarp (Dipterocarpaceae) forests which produce resin and tropical forest moisture (Rasmussen, 2008) that contribute to the survival of stingless bees. The Malaysian Agricultural Research and Development Institute (MARDI, 2013) reported that 30 species of stingless bees, generally harmless to humans, have been identified in Malaysia. Currently, nine stingless bee species have been found suitable for meliponiculture, viz. Heterotrigona erythrogastra, Lepidotrigona doipaensis, Lepidotrigona latipes, Lepidotrigona terminata, Platytrigona, Tetragonila atripes, Tetragonila collina, Heterotrigona itama and Geniotrigona thoracica. However, only two (H. itama and G. thoracica) are widely domesticated owing to the higher volume of honey produced as compared with other species. Honey from stingless bees is frequently consumed as a health supplement. There have been studies showing that such honey is valuable in the treatment of various diseases (Souza et al., 2006). For example, stingless bee honey has been reported to have properties that render them anti-inflammatory (Borsato et al., 2014), anti-cancer (Yazan et al., 2016), and anti-microbial (Zainol et al., 2013). The honey is also reputed to possess antioxidant properties (Duarte et al., 2012). Malaysia currently faces a deficit in local honey production and depends on imported honey from countries such as Australia and China. Local demand for honey is on the rise because of higher population growth and increased disposable income in the country, as well as consumers' increasing awareness of health-related foods and supplements. As shown in Figure 1, the amount of honey imported had consistently exceeded its export from 2011 to 2018 . The increasing demand for honey occurs due to the growing population and disposable income in the country, as well as the consumers' awareness of healthy foods and lifestyle.

Stingless bees commonly build nests in existing hollowed out parts of trees and in buildings. This behaviour offers the opportunity for the insects to be intensively domesticated, offering a source of income for residents in rural areas. In this connection, standard operating procedures need to be observed in farms for the industry to be successful. The empowerment of current stingless beekeepers contributes directly to the better production of high-quality honey (Mustafa et al., 2018). Yet, the stingless bee honey industry is in stagnation due to a 


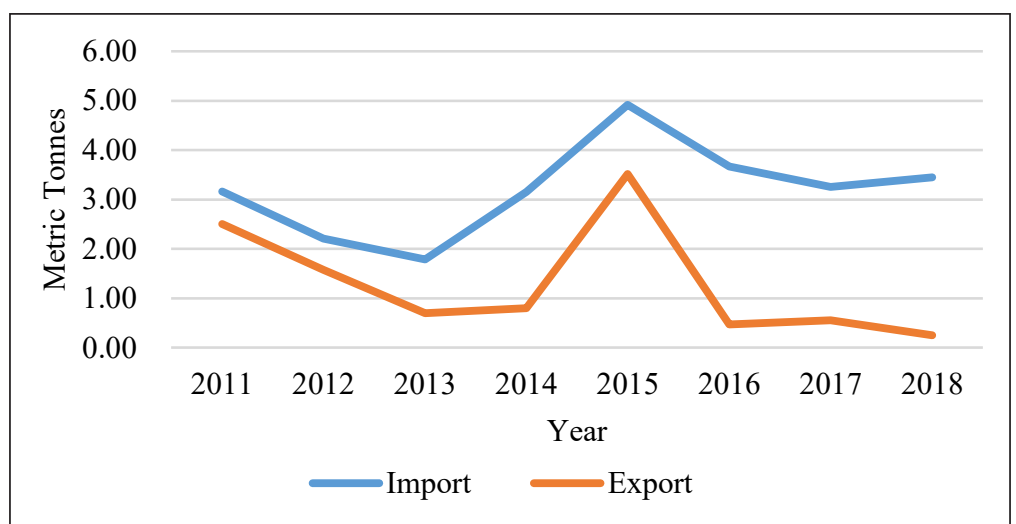

Figure 1. Honey statistic of import and export in Malaysia Source: United Nations Comtrade (2018)

paucity of research and development, thus leading to poor management, low honey production, and increasing costs (Saludin et al., 2019). The development of the modern beekeeping sector in Malaysia has attracted considerable attention from authorities in various sectors of the economy such as those related to production, marketing, and trade (Iryani, 2016). As commercial beekeepers in Malaysia are producing honey only as of the main output, proper farm management could increase productivity and efficiency while good cost management would minimize production expenditure and increase farm profits. One important indicator of production success is the efficiency of the farm. To be specific, economic efficiency is an important aspect as it is a crucial element in running a successful business.

Efficiency can be achieved by maximising honey production and minimising the cost of inputs. There is a paucity of research on the economic efficiency of honey bee farming in the world (Alropy et al., 2019; Ritten et al., 2018), and none on the economic efficiency of honey bee or stingless beekeeping in Malaysia. Hence, the purpose of this research is to evaluate the performance of commercial stingless beekeepers in Peninsular Malaysia via an economic efficiency assessment, and thence to identify the underlying factors in farm management responsible for any shortcomings. The findings would help stingless beekeepers and governmental policy-makers take appropriate action to optimise farm management input to maximise the output of honey from stingless beekeeping.

\section{Conceptual Framework}

Economic efficiency refers to the ability of certain firms to utilise and maximise all inputs or production factors to produce a maximum set of outputs. It covers both technical and allocative efficiencies, though it is more important to use technical efficiency as it stresses the efficient use of scarce resources. The Cost Data Envelopment Analysis (DEA) is a non-parametric approach to 
estimate the efficiency in production. This approach was originally developed by Charnes et al. (1978). The advantages of the DEA approach are that it does not require any explicit functional forms to specify the relationship between the inputs and output as well as it can easily accommodate multiple inputs (Coelli et al., 2002).

Basically, DEA is based on the technological assumptions of Constant Returns to Scale (CRS). Later on, Banker et al. (1984) extended this approach to accommodate the technologies that exhibited variable returns to scale (VRS). Our study adopted the CRS assumptions where increasing the input by one unit would generate an output of one unit. This assumption is suitable to be implemented when all DMUs are operating at an optimal scale. The CRS shows the total TE score by solving the linear programming (LP) based on the DEA model as shown in Eq. 1 (Charnes et al., 1978). We assumed that the single output production units (bee farms), henceforth referred to as the decisionmaking unit (DMU), made use of multiple inputs, $m$ in the production of output (honey). Then, $\mathrm{Yi}$ is the output, $\mathrm{Xi}$ is the vector of the inputs matrix $(\mathrm{m} \times 1), \mathrm{Y}$ is the vector of output matrix $(1 \times n)$, and $X$ is the $(\mathrm{m} \times \mathrm{n})$ input matrix of DMUs, where $\mathrm{n}=47$ and 28. Thus, the constrained optimization problem in the LP DEA can be stated as:

$$
\operatorname{Max}_{u, v}\left(u^{\prime} y_{i} / v^{\prime} x_{i}\right)
$$

Subject to

$u^{\prime} y_{j}-v^{\prime} x_{j} \leq 0$, where $j=1,2, \ldots . N$, and $u, v \geq 0$.
It should be noted that the DEA can also be used to measure cost efficiency. It is also important to clarify the efficiency scores obtained from the DEA model by studying the determinants of technical efficiency (Sherzod et al., 2018). In the CRS assumption, any DMUs with $\theta^{\text {crs }}=1$ are said to be on the frontier and technically efficient, while values $<1$ are below the frontier and technically inefficient. The technically efficient production cost of the $i^{\text {th }}$ DMU is stated as: ${ }^{P^{\prime}} i\left(\theta^{c r s} X i\right)$, where $P i$ is the vector of input price. In order to obtain the overall Economic Efficiency (EE) under the CRS assumption, the DEA LP constrained optimisation problem was solved as shown in Eq. 2.

Min $\mathrm{X} * \mathrm{i} \lambda, \mathrm{Pi} \mathrm{Xi}$; subject to: $\mathrm{Yi} \leq \mathrm{Y} \lambda$, $\mathrm{Xi} * \mathrm{X} \lambda, \lambda \geq 0$

where the cost minimisation objective or economically efficient input vector for the ith DMU is $\mathrm{Xi}$, and its price $P i$, and the output level, Yi. The total EE value for the ith farm was calculated as the ratio of the least cost to the actual cost using Eq. 3, where $\mathrm{EE}=1$ implies economically efficient, while $\mathrm{EE}<$ 1 signifies economically inefficient.

$$
\mathrm{EEi}=\mathrm{PiXi} * / \mathrm{PiXi}
$$

Furthermore, the Allocative Efficiency (AE) index is generated as shown in Eq. 4.

$$
\begin{aligned}
& \mathrm{AEi}=\mathrm{EEi} / \theta \mathrm{iCRS}= \\
& \text { PiiXi*,Pi( } \theta \text { iCRSXi) }
\end{aligned}
$$

where $\mathrm{AE}=1$ indicates that the $\mathrm{DMU}$ is allocatively efficient, while $\mathrm{AE}<1$ implies the highest amount of cost that 
the technically efficient DMU could save by using the least cost strategy (Chavas \& Aliber, 1993).

As introduced by Banker et al. (1984), Charnes et al. (1981), and Farrell (1957), the two most popular DEA models to measure technical efficiency are the inputoriented DEA, which considers how much the number of inputs could be reduced to produce the same level of output (and this model was applied here), while the second model is output-oriented DEA, which is concerned on how much the amount of output could be increased from the given set of inputs. The estimation of technical efficiency has subsequently been extended to accommodate multiple inputs and outputs (Coelli et al., 2005).

In the present study, after measuring technical, allocative, and cost efficiency scores in the DEA model, a second stage analysis that applied the Tobit regression model was used to determine the cause of inefficiency. This model was introduced by James Tobin in 1958 and is well- known as the censored regression model, where expected errors do not equal to zero (Amemiya, 1984). Therefore, the Tobit model is the most appropriate technique to handle characteristics of the distribution of censored efficiency scores in this study and it has also been widely used in many previous studies around the world. This study applied the following Tobit regression model and expressed it as follows:

$$
\bigcup_{i}^{\prime}=\beta_{o}+\sum_{j=1}^{k} \beta_{j} Z_{i j}+\mu_{i}
$$

Denoting $\mathrm{U}_{\mathrm{i}}$ as the observed dependent variables,

$$
\begin{aligned}
& U_{i}=1 \text { if } U_{i}^{*} \geq 1 ; \\
& U_{i}=U_{i}^{*} ; \text { if } 0<U_{i}^{*}<1 ; \\
& U_{i}=1 \text { if } U_{i}^{*} \leqslant 0 ;
\end{aligned}
$$

where $i \mathrm{U}$ is an efficiency measure representing technical efficiency with both CRS and VRS; allocative efficiency, cost efficiency, and scale efficiency of the i-th stingless beekeepers based on DEA estimation; * iU is the latent inefficiency variable; $\mathrm{Zi}$ is a vector of explanatory variables representing of farm characteristics; $\beta \mathrm{j}$ are unknown parameters to be estimated; $\mu_{\mathrm{i}}$ is the random error term that is independently and normally distributed with mean zero and common variance.

The empirical Tobit model specification is written as follows:

$$
\begin{aligned}
\mathrm{U}_{\mathrm{i}}= & \beta_{0}+\beta_{1} \mathrm{Z}_{1}+\beta_{2} \mathrm{Z}_{2}+\beta_{3} \mathrm{Z}_{3}+\beta_{4} \mathrm{Z}_{4} \\
& +\beta_{5} \mathrm{Z}_{5}+\beta_{6} \mathrm{Z}_{6}+\beta_{7} \mathrm{Z}_{7}+\beta_{8} \mathrm{Z}_{8}+\beta_{9} \mathrm{Z}_{9} \\
& +\beta_{10} \mathrm{Z}_{10}+\beta_{11} \mathrm{Z}_{11}+\beta_{12} \mathrm{Z}_{12} \mu
\end{aligned}
$$

Where:

$Z_{1}$ represents the age of stingless beekeepers $Z_{2}$ represents the gender of stingless beekeepers

$\mathrm{Z}_{3}$ represents the year of schooling of stingless beekeepers

$\mathrm{Z}_{4}$ represents the income of stingless beekeepers

$\mathrm{Z}_{5}$ represents the experience of stingless beekeepers

$\mathrm{Z}_{6}$ represents the agricultural officers' visits $\mathrm{Z}_{7}$ represents the full-time or part-time involvement in stingless beekeeping 
$\mathrm{Z}_{8}$ represents the family size

$Z_{9}$ represents the involvement of stingless beekeepers in an association

$Z_{10}, Z_{11}, Z_{12}$ represent the types of plants as sources of food for stingless bees.

\section{METHOD}

\section{Study Area and Data Collection}

In a cluster sampling exercise, stingless beekeepers were categorized into two regions in Peninsular Malaysia, namely the Northern region that comprised the states of Perlis, Kedah, Penang, and Perak, and the East Coast region that included the states of Kelantan, Terengganu, and Pahang. A random sampling of stingless beekeepers was undertaken from a list provided by the Agriculture Department. Primary data were collected through face-to-face interviews of commercial stingless beekeepers operating at least 50 stingless bee colonies. The data collected included detailed information on the costs involved in stingless bee honey production, their output, and related socioeconomic characteristics. In the Northern Region, 28 stingless beekeepers were interviewed while 47 respondents were from the East Coast region.

\section{Data Analysis}

Descriptive Study. The descriptive analysis of this study involved sociodemographic factors such as age, gender, years of education, marital status, size of the household, experience, visits by agricultural extension officers, involvement in associations, and full-time/part-time involvement. All of these factors were deemed to affect the efficiency of production. The information was summarised as mean, maximum, minimum, and standard deviation (Table 1).

Data Envelopment Analysis. Cost DEA in the DEAP version 2.1 Program was used to calculate cost efficiency (CE), technical efficiency (TE), and allocative efficiency (AE) of stingless bee farms. Three variables that were considered were (i) output, as revenue of honey production in Malaysian Ringgit (RM), (ii) input, as a number of hives, hours of labour and farm size (acres), and (iii) input costs, as cost of hives with colonies, labour costs and cost of Quit Rent (RM).

Tobit Regression (Second Stage Analysis). The Tobit regression model is an econometric model where the dependent variable is limited or censored at both sides. This study applied Tobit regression as a second stage analysis on the relationship between the efficiency measure and other relevant external factors that affected the efficiency of the farms. In this stage, 11 external factors were identified, namely 1) years of schooling, 2) family size, 3) gender, 4) age, 5) experience, 6) involvement in associations, 7) extension officer visits, 8) full or part-time involvement, and the types of plants available for stingless bee food sources such as 9) fruits, 10) flowers, and 11) acacia forest. 
RESULTS AND DISCUSSION

\section{Descriptive Statistics}

Table 1 presents a summary of sociodemographic variables associated with the stingless beekeeping industry. The results showed that for both geographical regions, most of the beekeepers were between 41 to 50 years old. Very few beekeepers were 61 years old and above, due perhaps to modern beekeeping involving technologies that may be difficult for older people to learn and practise. Adgaba et al. (2014) noted that in Saudi Arabia, only 5.49\% of

Table 1

Socio-demographic of stingless beekeepers in East Coast and Northern Region

\begin{tabular}{|c|c|c|c|c|}
\hline Categories & East Coast $(n=47)$ & Percentage & Northern $(n=28)$ & Percentage \\
\hline \multicolumn{5}{|l|}{ Age } \\
\hline $20-30$ & 7 & 15 & 1 & 4 \\
\hline $31-40$ & 7 & 15 & 5 & 18 \\
\hline $41-50$ & 14 & 30 & 11 & 39 \\
\hline $51-60$ & 13 & 28 & 5 & 18 \\
\hline $61-70$ & 4 & 9 & 6 & 21 \\
\hline Above 70 & 2 & 4 & 0 & 0 \\
\hline \multicolumn{5}{|l|}{ Gender } \\
\hline Male & 38 & 81 & 25 & 89 \\
\hline Female & 9 & 19 & 3 & 11 \\
\hline \multicolumn{5}{|l|}{ Education level } \\
\hline Primary school & 3 & 6 & 3 & 11 \\
\hline Secondary school & 25 & 53 & 14 & 50 \\
\hline Higher education & 19 & 40 & 11 & 39 \\
\hline \multicolumn{5}{|l|}{ Experience } \\
\hline $1-3$ years & 6 & 13 & 0 & 0 \\
\hline 4-6 years & 32 & 68 & 15 & 54 \\
\hline $7-9$ years & 7 & 15 & 11 & 39 \\
\hline 10 year and above & 2 & 4 & 2 & 7 \\
\hline \multicolumn{5}{|l|}{ Involvement } \\
\hline $1=$ Full time & 11 & 23 & 17 & 61 \\
\hline $2=$ Part time & 36 & 77 & 11 & 39 \\
\hline \multicolumn{5}{|l|}{ Family size } \\
\hline $1-3$ & 12 & 26 & 9 & 32 \\
\hline $4-6$ & 25 & 53 & 12 & 43 \\
\hline $7-9$ & 9 & 19 & 5 & 18 \\
\hline 10 and above & 1 & 2 & 2 & 7 \\
\hline \multicolumn{5}{|l|}{ Officer Visit } \\
\hline $1-3$ & 22 & 47 & 11 & 39 \\
\hline $4-6$ & 13 & 28 & 5 & 18 \\
\hline $7-9$ & 2 & 4 & 0 & 0 \\
\hline 10 and above & 10 & 21 & 12 & 43 \\
\hline \multicolumn{5}{|l|}{ Off farm Income } \\
\hline 1500 and less & 17 & 36 & 2 & 7 \\
\hline $1501-3000$ & 21 & 45 & 9 & 32 \\
\hline $3001-4500$ & 1 & 2 & 5 & 18 \\
\hline Above 4500 & 8 & 17 & 12 & 43 \\
\hline
\end{tabular}

Source: Field survey 2019 
the beekeepers were below 30 years old, $18.13 \%$ were between the ages of 30 and 40 , and the remaining $76.37 \%$ were over 40 years old. The number of beekeepers who were between 20 and 30 years old was very small. The high initial start-up costs for hives and other equipment might be a deterrence to young people.

In terms of gender participation, male beekeepers dominated the industry in this survey, comprising more than $80 \%$ of the total respondents for both study areas. About half of the beekeepers in the East Coast and Northern regions had completed secondary school (53\%, 50\% respectively). The number of beekeepers who attended higher education in the East Coast and Northern regions was also quite high (40\%, 30\% respectively). Onwumere et al. (2012) noted that in Abia State, Nigeria, a high proportion of secondary school leavers (43\%) were involved in modern beekeeping as they could cope with learning and practising the intricacies of modern beekeeping. Generally, an educated person would have a better chance of success to justify the large initial capital needed to start up a stingless bee farm, e.g. the costs of area preparation, purchase of hives, and various tools. Moreover, managing a stingless bee farm involves many technical skills such as harvesting, storing, and packaging honey correctly to preserve its quality. In contrast, alternative farming activities such as paddy farming are less technically demanding for which minimally skilled labour would suffice. While education should theoretically be advantageous in acquiring the competencies and entrepreneurial skills required by beekeepers, Joshi (2001) noted that benefits from higher education would only be realised in the modern agricultural sector rather than in traditional agriculture. The analysis showed that all beekeepers were experienced in beekeeping. For both the East Coast and Northern regions, the highest percentages $(68 \%, 54 \%$ respectively) were recorded for those with 4 to 6 years of experience. However, only a few beekeepers in the East Coast region (4\%) and the Northern region (7\%) had more than ten years of beekeeping experience.

The most common family size in both areas was 4 to 6 people, this being true for $53 \%$ in the East Coast region and $43 \%$ in the Northern region. The results also revealed the frequency of extension officer visits to the farm, bearing in mind that the industry was relatively new. In the East Coast region, $47 \%$ of beekeepers reported that they were visited only 1 to 3 times a year. For the Northern region, on the other hand, $43 \%$ of the beekeepers reported that they were visited more than 10 times a year. Household income other than income from beekeeping was used to measure the ability of farmers to procure initial capital. The results showed that for the East Coast region, $45 \%$ of beekeepers had incomes in the range of RM1501 to RM 3000, while in the Northern Region, $43 \%$ of the beekeepers had a household income exceeding RM4500.

\section{Farm Input and Output Variables}

The single output involved in the analysis was revenue from honey production. The inputs were farm size, number of hives, 
labour hours, and the input costs for Quit Rent, hives, and labour (Table 2).

These inputs were the key components in the production of stingless bee honey and they contributed to the total production cost.

\section{Efficiency Measurement}

Table 3 shows the cost DEA analysis under the CRS assumption. The table presents distribution scores of technical efficiency (TE), allocative efficiency (AE), and cost efficiency (CE) in the East Coast and Northern regions. For the East Coast region, the minimum, mean and maximum TE scored were $0.139,0.656$, and 1.00 respectively, while for the Northern region, the corresponding scores were $0.057,0.385$, and 1.00. The difference between the mean values of the two regions was quite high. It is noted here that for the East Coast region, the input was more efficiently deployed than for the Northern region but stingless beekeepers in the former would still have to reduce input by up to $35 \%$, which is a large amount, to optimise output.

In the Northern region, most of the bee farms $(61 \%)$ achieved TE scores of less than 0.300 , a very low value. This meant that the inputs were not efficiently utilised, and they needed to be lowered by up to $70 \%$ in order to achieve the optimum output efficiency.

As shown in Figure 2, the distribution of TE in the Northern region varied widely. Nevertheless, the highest score of 1.00, which indicated full efficiency, was attained by $17 \%$ of bee farms in the East Coast region and by $14 \%$ of farms in the Northern region.

Table 2

Farm input and output variables

\begin{tabular}{|c|c|c|c|c|c|c|}
\hline Variables & $\begin{array}{l}\text { Unit of } \\
\text { Measure }\end{array}$ & Region & Mean & Minimum & Maximum & $\begin{array}{c}\text { Std } \\
\text { Deviation }\end{array}$ \\
\hline \multirow{2}{*}{ Output Revenue } & \multirow{2}{*}{$\mathrm{RM}$} & East Coast & 39422.98 & 6000.00 & 99360.00 & 21205.46 \\
\hline & & Northern Region & 47979.52 & 6750.00 & 144000.00 & 36132.28 \\
\hline \multicolumn{7}{|l|}{ Input } \\
\hline \multirow{2}{*}{ Farm size } & \multirow{2}{*}{ Acre } & East Coast & 1.44 & 0.25 & 4.50 & 1.15 \\
\hline & & Northern Region & 3.24 & 0.25 & 10.50 & 2.98 \\
\hline \multirow{2}{*}{ Hive } & \multirow{2}{*}{ number } & East Coast & 75.72 & 50.00 & 230.00 & 38.38 \\
\hline & & Northern Region & 98.64 & 50.00 & 254.00 & 60.80 \\
\hline \multirow{2}{*}{ Labour } & \multirow{2}{*}{ Hour } & East Coast & 1590.38 & 288.00 & 8736.00 & 1513.79 \\
\hline & & Northern Region & 2399.54 & 48.00 & 16584.00 & 3944.91 \\
\hline \multicolumn{7}{|c|}{ Cost/price of Input used } \\
\hline \multirow{2}{*}{ Quite rent } & \multirow{2}{*}{$\mathrm{RM}$} & East Coast & 328.23 & 50.00 & 1000.00 & 254.97 \\
\hline & & Northern Region & 4076.35 & 25.00 & 70000.00 & 13383.65 \\
\hline \multirow{2}{*}{ Hive cost } & \multirow{2}{*}{$\mathrm{RM}$} & East Coast & 37791.49 & 5000.00 & 115000.00 & 21668.48 \\
\hline & & Northern Region & 50737.50 & 6000.00 & 230000.00 & 52185.38 \\
\hline \multirow{2}{*}{ Labour cost } & \multirow{2}{*}{$\mathrm{RM}$} & East Coast & 16534.47 & 3000.00 & 57600.00 & 11165.47 \\
\hline & & Northern Region & 34879.71 & 2880.00 & 113040.00 & 31823.89 \\
\hline
\end{tabular}


Norhidayah Che Soh, Nur Syahirah Samsuddin and Mohd Mansor Ismail

Table 3

Economic efficiency of stingless bee farming in East Coast and Northern Region

\begin{tabular}{|c|c|c|c|c|c|c|c|c|c|c|c|c|}
\hline \multirow[b]{3}{*}{ RANGE } & \multicolumn{4}{|c|}{ Technical Efficiency } & \multicolumn{4}{|c|}{ Allocative Efficiency } & \multicolumn{4}{|c|}{ Cost Efficiency } \\
\hline & \multicolumn{2}{|l|}{$\mathrm{EC}$} & \multicolumn{2}{|c|}{ NR } & \multicolumn{2}{|l|}{$\mathrm{EC}$} & \multicolumn{2}{|c|}{ NR } & \multicolumn{2}{|c|}{$\mathrm{EC}$} & \multicolumn{2}{|c|}{ NR } \\
\hline & freq(n) & $\%$ & freq(n) & $\%$ & freq(n) & $\%$ & freq $(n)$ & $\%$ & freq $(n)$ & $\%$ & freq(n) & $\%$ \\
\hline $0.0-0.099$ & 0 & 0 & 2 & 7 & 2 & 4 & 5 & 18 & 10 & 21 & 15 & 54 \\
\hline 0.1-0.199 & 4 & 9 & 12 & 43 & 5 & 11 & 4 & 14 & 14 & 30 & 4 & 14 \\
\hline $0.2-0.299$ & 3 & 6 & 3 & 11 & 8 & 17 & 5 & 18 & 5 & 11 & 6 & 21 \\
\hline $0.3-0.399$ & 5 & 11 & 0 & 0 & 8 & 17 & 3 & 11 & 4 & 9 & 1 & 4 \\
\hline $0.4-0.499$ & 4 & 9 & 2 & 7 & 7 & 15 & 0 & 0 & 4 & 9 & 0 & 0 \\
\hline $0.5-0.599$ & 5 & 11 & 3 & 11 & 4 & 9 & 4 & 14 & 5 & 11 & 0 & 0 \\
\hline $0.6-0.699$ & 2 & 4 & 1 & 4 & 5 & 11 & 1 & 4 & 1 & 2 & 0 & 0 \\
\hline $0.7-0.799$ & 5 & 11 & 0 & 0 & 3 & 6 & 1 & 4 & 2 & 4 & 0 & 0 \\
\hline 0.8-0.899 & 5 & 11 & 0 & 0 & 3 & 6 & 2 & 7 & 1 & 2 & 0 & 0 \\
\hline 0.9-0.999 & 6 & 13 & 1 & 4 & 2 & 4 & 2 & 7 & 1 & 2 & 1 & 4 \\
\hline 1.000 & 8 & 17 & 4 & 14 & 0 & 0 & 1 & 4 & 0 & 0 & 1 & 4 \\
\hline Mean & \multicolumn{2}{|c|}{0.656} & \multicolumn{2}{|c|}{0.385} & \multicolumn{2}{|c|}{0.445} & \multicolumn{2}{|c|}{0.404} & \multicolumn{2}{|c|}{0.291} & \multicolumn{2}{|c|}{0.172} \\
\hline Min. Efficiency & \multicolumn{2}{|c|}{0.139} & \multicolumn{2}{|c|}{0.057} & \multicolumn{2}{|c|}{0.056} & \multicolumn{2}{|c|}{0.009} & \multicolumn{2}{|c|}{0.039} & \multicolumn{2}{|c|}{0.001} \\
\hline Max. Efficiency & \multicolumn{2}{|l|}{1} & \multicolumn{2}{|l|}{1} & \multicolumn{2}{|c|}{0.907} & \multicolumn{2}{|l|}{1} & \multicolumn{2}{|c|}{0.907} & \multicolumn{2}{|c|}{1} \\
\hline Std. Deviation & \multicolumn{2}{|c|}{0.288} & \multicolumn{2}{|c|}{0.329} & \multicolumn{2}{|c|}{0.239} & \multicolumn{2}{|c|}{0.317} & \multicolumn{2}{|c|}{0.224} & \multicolumn{2}{|c|}{0.244} \\
\hline
\end{tabular}

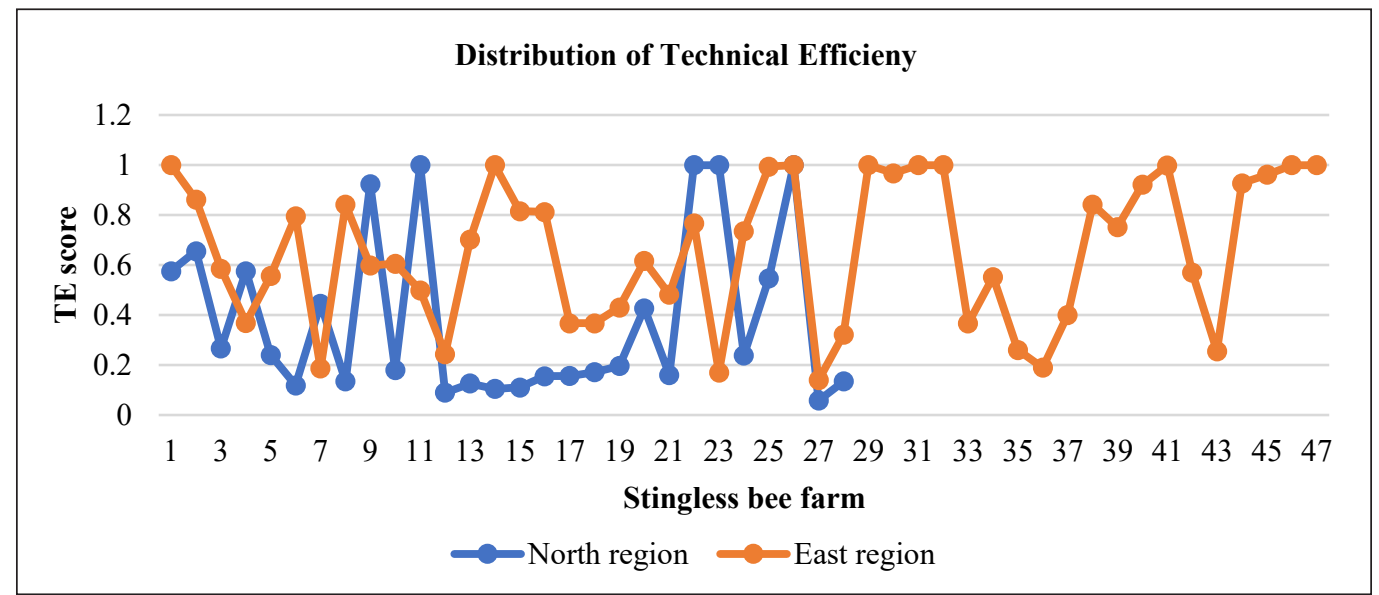

Figure 2. TE's distribution of bee farms in the East Coast and Northern Region

Allocative efficiency (AE) is measured East Coast region, there were two ranges of by the ratio of the minimum costs required by the Decision Making Unit (DMU) to AE scores (0.2 to 0.299 and 0.3 to 0.399 ), produce a given level of output and the actual costs of the DMU adjusted for TE which were the highest attained by $17 \%$ of farms. None of the farms surveyed in (Farrell, 1957). Figure 3 shows that in the the East Coast region was fully allocative efficient, i.e. achieving a score of 1.00 . For 


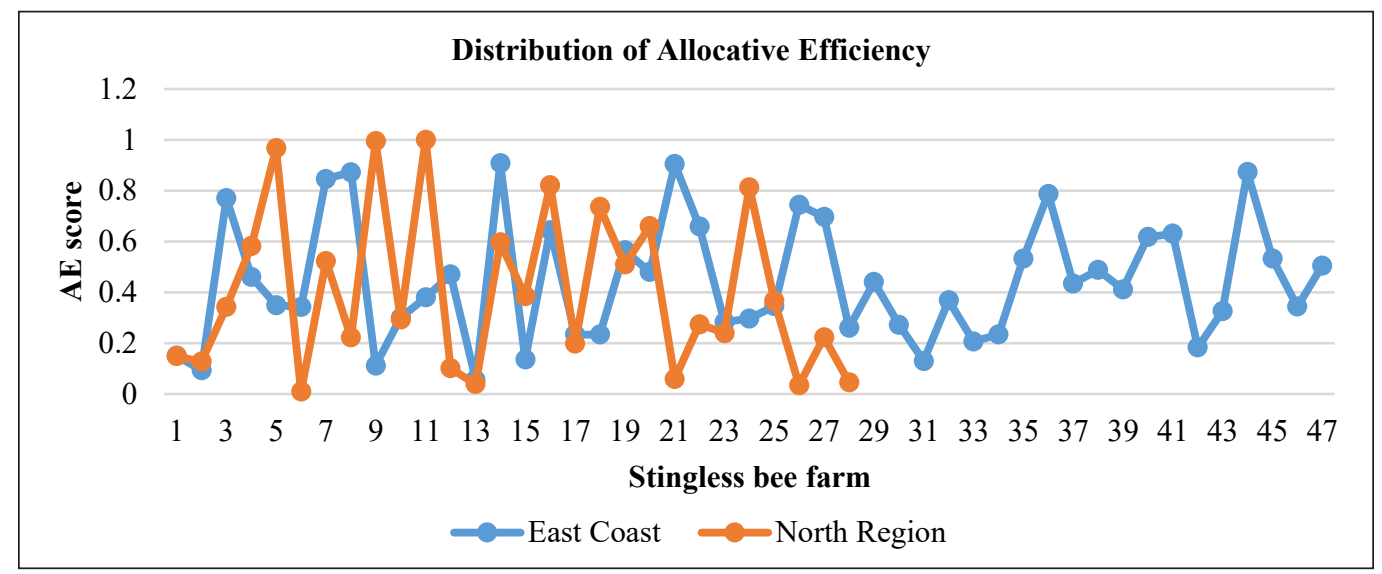

Figure 3. AE's distribution of bee farm in East Coast and North Region

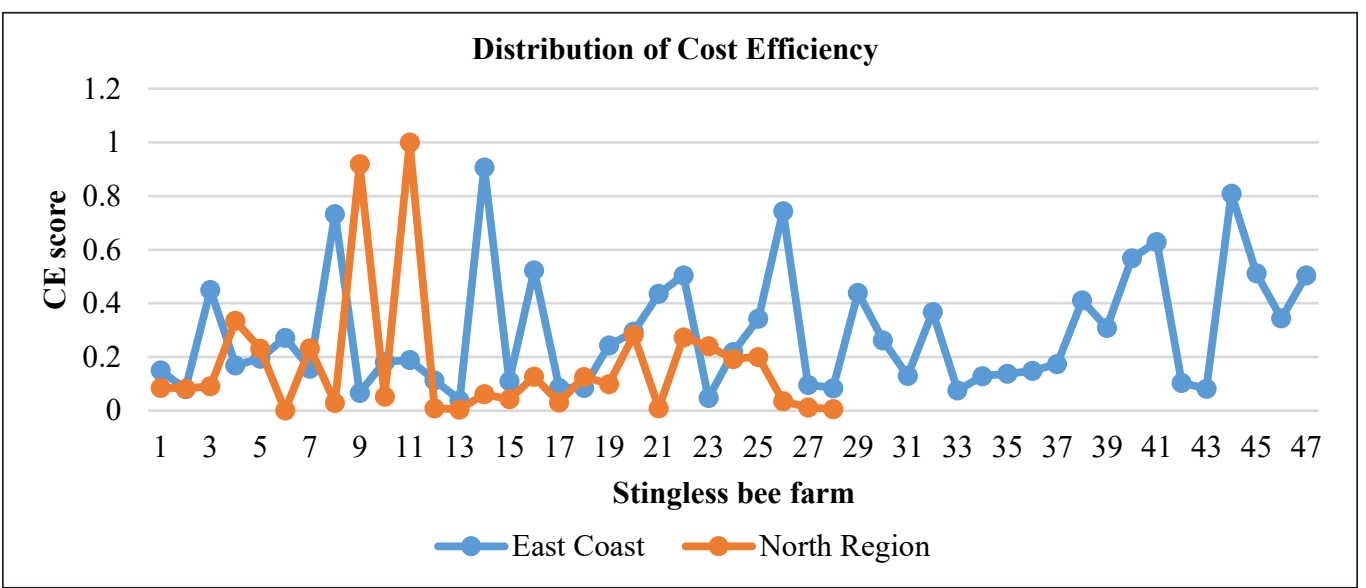

Figure 4. CE's distribution of bee farms in the East Coast and Northern Region

the Northern region, one farm did attain a score of 1.00. Two ranges of scores $(0.00$ to 0.099 and 0.2 to 0.299 ) representing the highest frequencies were applicable to $18 \%$ of the farms. Farms in the East Coast region showed a mean $\mathrm{AE}$ score of 0.445 , a minimum of 0.056 , and a maximum of 0.907. For the Northern Region, the AE mean, minimum, and maximum scores were 0.404, 0.009, and 1.000 respectively.

The data on input (quantity and prices) and output were analysed using the Cost efficiency (CE) DEA programme. Any efficiency measurement that uses more data obtained from DMUs is deemed more reliable than other efficiency measures (Jahanshahloo et al., 2011). In this study, therefore, the cost-efficiency evaluated the ability of the stingless bee farm to produce the current output at a minimal cost, given its input prices. From Table 3 and Figure 4 , it can be seen that the majority of the farms attained lower CE scores in the East Coast region, with $30 \%$ of the farms falling 
in the range of 0.1 to 0.199 , followed by $21 \%$ in the 0.00 to 0.099 range and $11 \%$ in the 0.2 to 0.299 range. For the Northern region, the values achieved were lower, where $54 \%$ of the farms had CE scores of only 0.00 to 0.099 , followed by $21 \%$ with scores of 0.2 to 0.299 and $11 \%$ scoring 0.1 to 0.199 . Hence, the scores of cost efficiency were lower for both regions in comparison with technical efficiency and allocative efficiency. CE scores in both the East Coast and Northern regions were very variable, with mean, minimum, and maximum scores of $0.291,0.039$, and 0.907 respectively. Corresponding scores in the Northern Region were 0.172, 0.001, and 1.00. Essentially, CE scores were strongly influenced by the TE and AE scores. Cost efficiency can be described as the effective choice of inputs in relation to expenditure with the aim of minimising production costs, whereas technical efficiency investigates how well the production process converts inputs into outputs. AE, on the other hand, involves managerial decisions to be implemented at the farm to lower costs for profits to increase. Generally, a low AE score would cause the $\mathrm{CE}$ value also to be low.

Referring to Table 2, the cost of hives (with colonies) and labour constituted the highest share of the expenditure as compared to expenditure for Quit Rent. To increase the $\mathrm{CE}$ of the farm, the cost of hives can be reduced by stingless beekeepers setting up the beehives and colonies themselves using appropriate methods and material, instead of purchasing them. Here, government institutions can play a role to keep the prices of hives and colonies affordable. Much of the costs and time on labour were spent on the manual honey recovery ("sucking") process which was quite complicated. The use of a mechanical aspirator is suggested to reduce the time spent on this process. Costs can be reduced if the beekeepers perform this process themselves instead of assigning the task to hired help.

\section{Determination of Factors Leading to Inefficiency}

In order to determine resource (technical, allocative, and cost) efficiency, the independent variables were separately regressed on selected demographic, socioeconomic, and other farm variables. The impacts of these factors that possibly influenced the stingless beekeeping efficiency (or inefficiency) were analysed by using the Tobit regression model. As presented in Table 4, on the East Coast, the age of beekeepers contributed an insignificant influence and carried a negative sign which means that older beekeepers were technically more efficient than younger beekeepers. In contrast, for the Northern region, the influence of age on TE carried a positive sign and was significant at $\mathrm{p}<.1$, meaning that younger beekeepers were technically more efficient than older beekeepers. The gender of beekeepers was not statistically significant in both regions and for each aspect of efficiency. However, the sign was positive, meaning that farms managed by males had reduced technical inefficiency. The analysis showed 
different results in the two regions for years of schooling. In the East Coast, the relationships with $\mathrm{TE}$ and $\mathrm{CE}$ were negative and significant $(p<.05)$. On the other hand, the relationships in the Northern region were positive and significant for the same independent efficiency variables. The results, therefore, suggested that bettereducated beekeepers in the Northern region were more technically efficient and more cost-efficient compared to less educated beekeepers. On the other hand, the converse was true for beekeepers in the East Coast region.

Household income presented no significant effects. This variable carried a positive sign for $\mathrm{TE}$ and a negative sign for $\mathrm{AE}$ and $\mathrm{CE}$ for the East Coast, while for the Northern Region, the relationship was negative for TE and CE while it was positive for AE. As shown in Table 4, the experience of beekeepers was statistically not significant but carried a positive sign for the East Coast region, meaning that increasing beekeepers experience increased the technical inefficiency of the bee farming, whereas, for the Northern region, the results showed a negative sign. Table 4 indicated that extension officer visits had a significant influence at $\mathrm{p}<.1$ for the East Coast region and $\mathrm{p}<.05$ for the Northern region, with the relationship in both regions carrying negative signs. Extension officer visits are important as such agriculture officers support beekeepers in terms of knowledge, technology transfer, and allocation of government incentives to improve farm productivity and increase the market share of locally produced honey. The results indicated that the more often officers visited the farms, the less inefficiency prevailed. In terms of whether the involvement of beekeepers had been part-time or full time, the sign was negative for AE in the East Coast region, and it indicated a significant influence at $p<.05$. This result indicated that if beekeepers were involved as part-timers, the efficiency of the stingless beekeeping increased compared to doing it full time. However, the results for the Northern region were the opposite where the TE carried a positive sign, meaning full-time beekeepers were more technically efficient. The result for the family size was not significant for the East Coast but indicated positive effects for TE, AE, and CE which showed that larger family size increased the inefficiency of the farms. In the Northern region, a negative sign was attached to family size for $\mathrm{AE}$, significant at $\mathrm{p}<.1$, which meant an increase in family members raised the efficiency of the farm. Many beekeepers join professional associations to obtain the benefits that they offer and to exchange ideas and technologies with other members. Moreover, such associations commonly provide seminars and training to enhance beekeepers' skills. Nevertheless, as noted in Table 4, the influence of membership in associations was not significant. However, this variable carried a positive sign for both regions, meaning associations helped to support beekeepers in increasing the technical efficiency of the farms.

In the wild, the stingless bees depend on the food sources around their nest, e.g. flowers, fruits, and trees. If the food 
Norhidayah Che Soh, Nur Syahirah Samsuddin and Mohd Mansor Ismail

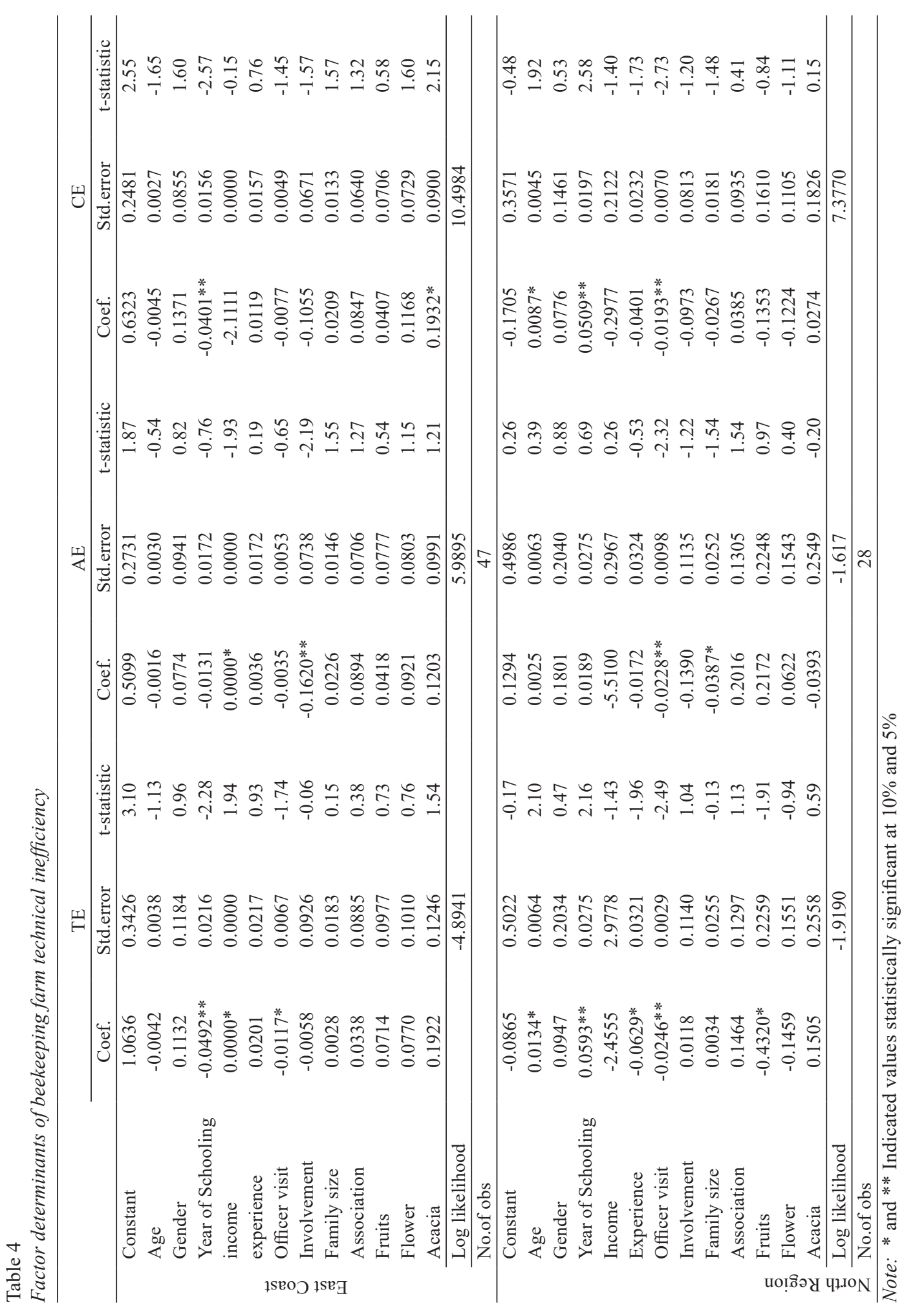


supply in nature is insufficient, they move to other areas that provide enough food for their colony's survival. Therefore, in the beekeeping industry, the food source is an essential element to be considered by beekeepers. In addition to wild and existing plants in the vicinity of the farm, beekeepers should grow flowering plants that produce nectar and pollen around the farm area. Especially useful are plants that flower throughout the year and the acacia tree is a known nectar source. Based on the results of this study, however, the contribution of fruits, flowers, and acacia trees was not significant. However, positive signs were noted for the East Coast region, which showed that the planting of such plants contributed to the TE, AE, and CE of the farms. For the Northern region, fruits and flowers carried a negative sign for TE and CE. A positive sign was noted for acacia in relation to $\mathrm{TE}$ and $\mathrm{CE}$.

\section{CONCLUSION}

This research revealed that most of the stingless beekeepers were not economically efficient in utilising scarce resources. Farm managers should be made aware of better ways to reduce inefficiencies and production costs in order to increase profits. The study revealed how efficiency might be increased by addressing factors such as: age of beekeepers, level of education, frequency of farm visits by agriculture officers, the length of experience in stingless beekeeping, and the availability of fruits as food and pollen sources for stingless bees. This industry is considered relatively new in Malaysia and, therefore, the results of this study can give an impetus to the Malaysian government and policymakers to assist stingless beekeepers to increase the economic efficiency of their farms so that they can be sustainable. It is suggested that a similar study be undertaken in the East Malaysian states of Sabah and Sarawak.

\section{ACKNOWLEDEGEMENT}

The authors wish to acknowledge the financial support received from the TRGS research grant no. TRGS/1/2016/ UPM/01/5/1 provided by the Ministry of Education, Malaysia.

\section{REFERENCES}

Adgaba, N., Al-Ghamdi, A., Shenkute, A. G., Ismaiel, S., Al-Kahtani, S., Tadess, Y., Ansari, M. J., Abebe, W., \& Abdulaziz, M. Q. A. (2014). Socio-economic analysis of beekeeping and determinants of box hive technology adoption in the Kingdom of Saudi Arabia. The Journal of Animal \& Plant Sciences, 24(6), 1876-1884.

Alropy, E. T., Desouki, N. E., \& Alnafissa, M. A. (2019). Economics of technical efficiency in white honey production: Using stochastic frontier production function. Saudi Journal of Biological Sciences, 26(7), 1478-1484. https:// doi.org/10.1016/j.sjbs.2019.09.029

Amemiya, T. (1984). Tobit models: A survey. Journal Economic, 24(1-2), 3-61. https://doi. org/10.1016/0304-4076(84)90074-5

Banker, R. D., Charnes, A., \& Cooper, W. W. (1984). Some models for estimating technical and scale inefficiencies in data envelopment analysis. Management Science, 30(9), 1078-1092. https:// doi.org/10.1287/mnsc.30.9.1078 
Borsato, D. M., Prudente, A. S., Boscardin, P. M., Borsato, A. V., Luz, C. F. P., Beatriz, H. L., Maia, N. S., Cabrini, D. A., Otuki, M. F., Miguel, M. D., Farago, P. V., \& Miguel, O. G. (2014). Topical anti-inflammatory activity of a monofloral honey of Mimosa scabrella provided by Melipona marginata during winter in Southern Brazil. Journal of Medicinal Food, 17(7), 817-825. https://doi.org/10.1089/jmf.2013.0024

Charnes, A., Cooper, W. W., \& Rhodes, E. (1978). Measuring the efficiency of decision making units. European Journal of Operational Research, 2(6), 429-444. https://doi.org/10.1016/03772217(78)90138-8

Charnes, A., Cooper, W. W., \& Rhodes, E. (1981). Evaluating program and managerial efficiency: An application of data envelopment analysis to program follow through. Management Science, 27(6), 668-697. https://doi.org/10.1287/ mnsc. 27.6 .668

Chavas, J. P., \& Aliber, M. (1993). An analysis of economic efficiency in agriculture: A nonparametric approach. Journal Agriculture Resource Economics, 18(1), 1-16. https://doi. org/10.22004/ag.econ.30811

Coelli, T., Rahman, S., \& Thirtle, C. (2002). Technical, allocative, cost and scale efficiencies in Bangladesh rice cultivation: A nonparametric approach. Journal Agricultural Economic, 53(3), 607-626. https://doi. org/10.1111/j.1477-9552.2002.tb00040.x

Coelli, T. J., Rao, D. S. P., O’Donnell, C. J., \& Battese, G. E. (2005). An introduction to efficiency and productivity analysis (2nd ed.). Springer.

Duarte, A. W. S., Vasconcelos, M. R. S., Menezes, A. P. D., Silva, S. C., Souza, M. O., \& López, A. M. Q. (2012). Composition and antioxidant activity of honey from Africanized and stingless bees in Alagoas (Brazil): A multivariate analysis. Journal of Apicultural Research, 51(1), 23-35. https://doi.org/10.3896/IBRA.1.51.1.04
Farrell, M. J. (1957). The measurement of productive efficiency. Journal of the Royal Statistical Society, Series A, 120(3), 253-290. https://doi. org/10.2307/2343100

Iryani, W. I. W. (2016). A review on beekeeping in Malaysia: History, importance and future directions. Journal of Sustainability Science and Management, 11(2), 70-80.

Ismail, M. M. (2014). Competitiveness of beekeeping industry in Malaysia. UPM Press.

Jahanshahloo, G. R., Hosseinzadeh Lotfi, F., Jafari, Y., \& Maddahi, R. (2011). Selecting symmetric weights as a secondary goal in DEA crossefficiency evaluation. Applied Mathematical Modelling, 35(1), 544-549. https://doi. org/10.1016/j.apm.2010.07.020

Joshi, P. K. (2001). Education, technology adoption and agricultural productivity. Indian Journal of Agricultural Economics, 56(1), 33-37. https:// doi.org/10.22004/ag.econ.297795

Malaysian Agricultural Research and Development Research. (2013, January 22). MARDI kumpul 30 spesies Kelulut [MARDI collected 30 species of Stingless bee] https://www.kelablebahkelulut. com/2015/01/mardi-kumpul-30-spesies-kelulutharian.html

Mustafa, M. Z., Yaacob, N. S., \& Sulaiman, S. A. (2018) Reinventing the honey industry: Opportunities of the stingless bee. The Malaysian Journal of Medical Sciences, 25(4), 1-5. https:// doi.org/10.21315/mjms2018.25.4.1.

Onwumere, J., Onwukwe, F., \& Alamba, C. S. (2012). Comparative analyses of modern and traditional bee keeping entrepreneurships in Abia State, Nigeria. Journal of Economics and Sustainable Development, 3(13), 1-9.

Rasmussen, C. (2008). Catalog of the Indo-Malayan/ Australasian stingless bees (Hymenoptera: Apidae: Meliponini) (Zootaxa 1935). Magnolia Press. https://doi.org/10.11646/zootaxa.1935.1.1 
Rasmussen, C., \& Cameron, S. A. (2010). Global stingless bee phylogeny supports ancient divergence, variance, and long distance dispersal. Biological Journal of the Linnean Society, 99(1), 206-232. https://doi.org/10.1111/j.10958312.2009.01341.x

Ritten, C. J., Peck, D., Ehmke, M., \& Patalee, M. A. B. (2018). Firm efficiency and returns-to-scale in the honey bee pollination services industry. Journal of Economic Entomology, 111(3), 10141022. https://doi.org/10.1093/jee/toy075

Saludin, S. F., Kamarulzaman, N. H., \& Ismail, M. M. (2019). Measuring consumers' references of stingless bee honey (meliponine honey) based on sensory characteristics. International Food Research Journal, 26(1), 225-235.

Sherzod, B., Kim, K., \& Lee, S.H. (2018). Agricultural transition and technical efficiency: An empirical analysis of wheat-cultivating farms in Samarkand Region. Uzbekistan Sustainability, 10(9), 3232. https://doi.org/10.3390/su10093232

Slaa, E., Chaves, L., Malagodi-Braga, K., \& Hofstede, F. E. (2006). Stingless bees in applied pollination:
Practice and perspectives. Apidologie, 37(2), 293-315. https://doi.org/10.1051/apido:2006022

Souza, B., Roubik, D., Barth, O., Heard, T., Enríquez, E., Carvalho, C., Villas-BoAs, J., Almeida, M. L., Bogdanov, S., \& Vit, P. (2006). Composition of stingless bee honey: Setting quality standards. Interciencia, 31(12), 867-875.

United Nations Comtrade. (2018). World merchandise exports and imports by commodity (HSO2). https://comtrade.un.org/ data/

Yazan, L. S., Zali, M. F. S. M., Ali, R. M., Zainal, N. A., Esa, N., Sapuan, S., \& Alwi, S. S. S. (2016). Chemopreventive properties and toxicity of Kelulut honey in Sprague Dawley rats induced with azoxymethane. BioMed Research International, 2016, 4036926. https:// doi.org/10.1155/2016/4036926

Zainol, M. I., Yusoff, K. M., \& Yusof, M. Y. M. (2013). Antibacterial activity of selected Malaysian honey. BMC Complementary and Alternative Medicine, 13(1), 1-10. http://doi. org/10.1186/1472-6882- 13-129 
